\title{
Quantifying the Contribution of Lubrication Oil Carbon to Particulate Emissions from a Diesel Engine
}

\author{
B. A. Buchholz, R. W. Dibble, D. Rich, A. S. Cheng
}

This article was submitted to Japan Society of Automotive Engineers JSAE/SAE, Yokohama, Japan, May 19-22, 2003

U.S. Department of Energy

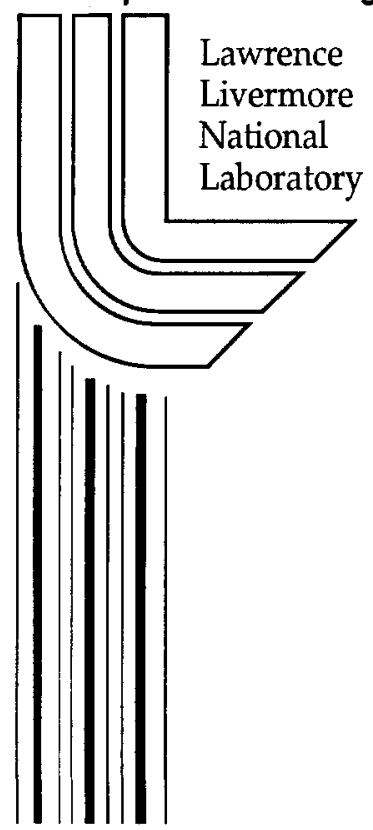

January 31, 2003 


\section{DISCLAIMER}

This document was prepared as an account of work sponsored by an agency of the United States Government. Neither the United States Government nor the University of California nor any of their employees, makes any warranty, express or implied, or assumes any legal liability or responsibility for the accuracy, completeness, or usefulness of any information, apparatus, product, or process disclosed, or represents that its use would not infringe privately owned rights. Reference herein to any specific commercial product, process, or service by trade name, trademark, manufacturer, or otherwise, does not necessarily constitute or imply its endorsement, recommendation, or favoring by the United States Government or the University of California. The views and opinions of authors expressed herein do not necessarily state or reflect those of the United States Government or the University of California, and shall not be used for advertising or product endorsement purposes.

This is a preprint of a paper intended for publication in a journal or proceedings. Since changes may be made before publication, this preprint is made available with the understanding that it will not be cited or reproduced without the permission of the author.

This work was performed under the auspices of the United States Department of Energy by the University of California, Lawrence Livermore National Laboratory under contract No. W-7405-Eng-48.

This report has been reproduced directly from the best available copy.

Available electronically at http://www.doc.gov/bridge

Available for a processing fee to U.S. Department of Energy

And its contractors in paper from

U.S. Department of Energy

Office of Scientific and Technical Information

P.O. Box 62

Oak Ridge, TN 37831-0062

Telephone: (865) 576-8401

Facsimile: (865) 576-5728

E-mail: reports@adonis.osti.gov

Available for the sale to the public from

U.S. Department of Commerce

National Technical Information Service

5285 Port Royal Road

Springfield, VA 22161

Telephone: (800) 553-6847

Facsimile: (703) 605-6900

E-mail: orders@ntis.fedworld.gov

Online ordering: http://www.ntis.gov/ordering.htm

OR

Lawrence Livermore National Laboratory

Technical Information Department's Digital Library

http://www.llnl.gov/tid/Library.html 
JSAE 20030100

SAE 2003-01-1987

\title{
Quantifying the contribution of lubrication oil carbon to particulate emissions from a diesel engine
}

\author{
Bruce A. Buchholz \\ Center for Accelerator Mass Spectrometry, Lawrence Livermore National Laboratory, Livermore, California USA \\ Robert W. Dibble and David Rich \\ Department of Mechanical Engineering, University of California, Berkeley, California USA
}

A.S. (Ed) Cheng

Department of Mechanical Engineering, California State University, Sacramento, California USA

Copyright $\odot 2003$ Society of Automolive Engineers of Japan, Inc.

\begin{abstract}
The contribution of lubrication oil to particulate matter (PM) emissions from a Cummins B5.9 Diesel engine was measured using accelerator mass spectrometry to trace carbon isotope concentrations. The engine operated at fixed medium load (285 N-m (210 ft.lbs.) at $1600 \mathrm{rm}$ ) used $100 \%$ biodiesel fuel (B100) with a contemporary carbon- $14\left({ }^{14} \mathrm{C}\right)$ concentration of 103 amol ${ }^{14} \mathrm{C} / \mathrm{mg} \mathrm{C}$. The ${ }^{14} \mathrm{C}$ concentration of the exhaust $\mathrm{CO}_{2}$ and $\mathrm{PM}$ were 102 and 99 amol ${ }^{14} \mathrm{C} / \mathrm{mg} \mathrm{C}$, respectively. The decrease in ${ }^{14} \mathrm{C}$ content in the $\mathrm{CO}_{2}$ and $\mathrm{PM}$ are due to the consumption of lubrication oil which is ${ }^{14} \mathrm{C}$-free. Approximately $4 \%$ of the carbon in $\mathrm{PM}$ came from lubrication oil under these operating conditions.
\end{abstract}

\section{INTRODUCTION}

Lubrication oil consumption has traditionally been a concern for well used engines, when wear produces larger gaps that contribute to transport of lubrication oil into the combustion chamber and out the exhaust port. The consumption of oil is a concern for proper engine operation. Aside from severe oil burners which produce visible smoke, the contribution of lubrication oil to emissions has been a minor concern. New engines properly maintained produce very little particulate matter (PM) from lubrication oil. The sensitivity of modern emission control catalysts to sulfur poisoning has led to increased interest in determining the quantity of oil transported through the cylinder and out the exhaust port. Also, although the mass of lubrication oil consumption is quite low, it has been implicated as a source of nano-particles.

Techniques for tracing sulfur from lubrication oil as a measurement of oil consumption are found in the literature over more than 20 years [1-4]. Methods using other elemental tracers such as calcium, magnesium, phosphorous and zinc have also been done [5-7]. These techniques are successful at tracing the specific elements measured, but do not necessarily reflect the behavior of lubrication oil carbon.

Some lubrication oil appears in the exhaust unchanged, i.e., no combustion. Following specific hydrocarbons from oil to PM is believed to indicate lube oil consumption without combustion [8]. Chemical tracing can identity noncombusted oil, but it cannot account for all the carbon from lube oil that is combusted. Tracer studies using deuterated (hydrogen replaced with deuterium) hydrocarbons indicated that paraffins in lube oil $\left(\mathrm{C}_{16}\right.$ and $\left.\mathrm{C}_{32}\right)$ are combusted and do not blow through intact [9]. An atomic tracer, rather than a chemical tracer, could account for all the carbon in PM contributed by lubrication oil.

Two carbon isotopes could be used as tracers. Carbon-13 $\left({ }^{13} \mathrm{C}\right)$ occurs naturally at $1.1 \%$ of all carbon. Because it is relatively common, it has a significant background for the mass spectrometry methods needed for detection. In turn, large amounts of labeled tracer are required to alter the isotopic concentration of ${ }^{13} \mathrm{C}$ in an oil or fuel volume. The longlived radioisotope carbon-14 $\left({ }^{14} \mathrm{C}\right)$ has a natural abundance of 1.2 parts per $10^{12}$ in atmospheric $\mathrm{CO}_{2}$ and living things. Carbon-14 concentration in petroleum is below 1 part in $10^{15}$ due to radioactive decay during millions of years underground. With this low intrinsic background, 10-13 orders of magnitude below ${ }^{13} \mathrm{C}$, it is easier to see small changes in ${ }^{14} \mathrm{C}$ if a sensitive detector is used. Accelerator mass spectrometry (AMS), a technique developed in the late 1970's for radiocarbon dating, is ideally suited for measuring these small changes in ${ }^{14} \mathrm{C}$ content $[10-$ 12]. 
Since we do not know a priori which carbon atoms will preferentially produce $P M_{1}$ a universal label is required. Obtaining uniformly labeled lubrication oil is a challenge. Synthesis of a uniformly labeled synthetic oil can be achieved by starting with a labeled base and polymerizing it to achieve a suitable distribution of poly-alpha-olefins (PAOs). Considerable skill in organic synthesis is required for this approach.

A simpler approach is to use a bio-derived hydrocarbon as the lube oil. The carbon atoms are universally labeled with ${ }^{14} \mathrm{C}$ and no radioactive components are needed. The drawback is that lubrication oils are complex mixtures which are not amenable to simple substitutions. We can circumvent this problem by an alternative approach: use a bioderived fuel and conventional lubrication oil. The ${ }^{14} \mathrm{C}$ concentration of the bio-derived fuel is three orders of magnitude greater than the oil. The contribution of lube oil-derived carbon to emissions is measured in a depression in ${ }^{14} \mathrm{C}$ concentration in $\mathrm{PM}$ and $\mathrm{CO}_{2}$ emissions.

\section{FACILITIES}

ENGINE FACILITY - Emission samples were collected from a 1993 Cummins B5.9 engine (Table 1) at the Combustion Analysis Laboratory at the University of California at Berkeley (UCB). Fuel injection is achieved with a Bosch P7100 PE type inline pump capable of injection pressures of up to $115 \mathrm{MPa}$. No modifications were made to the engine or fuel injection system to optimize for operation on the test fuel.

Table 1. Cummins B5.9 engine specifications

\begin{tabular}{|c|c|}
\hline Model year & 1993 \\
\hline Displacement & 5.88 liters $\left(359 \mathrm{in}^{3}\right)$ \\
\hline Configuration & 6 cylinder inline \\
\hline Bore & $102 \mathrm{~mm}$ (4.02 in) \\
\hline Stroke & $120 \mathrm{~mm}$ (4.72 in) \\
\hline Compression ratio & $17.6: 1$ \\
\hline Horsepower rating & $175 \mathrm{hp} @ 2500 \mathrm{rpm}$ \\
\hline Torque rating & $420 \mathrm{ft}-\mathrm{lb} @ 1600 \mathrm{rmm}$ \\
\hline Aspiration & turbocharged and aftercooled \\
\hline Injection timing & $11.5^{\circ} \mathrm{BTDC}$ \\
\hline
\end{tabular}

Fuel consumption was determined using a Micro Motion R025 coriolis flow meter. Modifications to the fuel return system were made to eliminate fuel return to the storage tank. The return line is instead routed back into the fuel delivery line and a shell-and-tube heat exchanger was installed to prevent overheating of the fuel in the short-circuited system. The alteration eliminated the need to install a return flow meter for accurately measuring fuel consumption and facilitated easier fuel changes. Gaseous emissions were monitored using Horiba gas analyzers as listed in Table 2. Measurements of PM were made via a mini- dilution tunnel designed and constructed by UCB (see Figure 1).

AMS FACILITY - The samples in this study were analyzed at the Center for AMS at Lawrence Livermore National Laboratory (LLNL) with the HVEE

Table 2. Equipment for gaseous emissions measurements

\begin{tabular}{|l|l|}
\hline $\mathrm{HC}$ & $\begin{array}{l}\text { Horiba Instruments FMA-220 flame ionization } \\
\text { analyzer }\end{array}$ \\
\hline $\mathrm{CO}, \mathrm{CO}_{2}$ & Horiba Instruments AIA-220 intrared analyzer \\
\hline $\mathrm{NO}_{\times}$ & $\begin{array}{l}\text { Horiba Instruments CLA-220 chemiluminescent } \\
\text { analyzer }\end{array}$ \\
\hline
\end{tabular}

FN system operating at 6.5 MV [13]. All samples were prepared in the LLNL natural carbon prep lab using established methods [14]. The AMS sample prep method accommodates samples containing between 0.05 and $10 \mathrm{mg}$ carbon. Samples containing 0.2-2 mg carbon are preferred for obtaining higher measurement precision and lower systemic backgrounds. Approximately $15000{ }^{14} \mathrm{C}$-AMS samples are measured annually at LLNL with 2-3 measurement days per week.

\section{MATERIALS}

TEST FUEL AND OIL - The fuel used in these tests was $100 \%$ Biodiesel obtained from CytoCulture, Point Richmond, CA USA. It was recycled vegetable oil. The fuel meets published biodiesel specifications [15]. The lubrication oil was Chevron Delo 400 Heavy Duty Motor Oil Multi-grade SAE 15W-40, API service classification; $\mathrm{CH}-4 / \mathrm{SJ}$. The ${ }^{14} \mathrm{C}$ content of fuel and oil was checked before starting the experiments. Biodiesel fuel contained a contemporary level of ${ }^{14} \mathrm{C}$, 103 attomole ${ }^{14} \mathrm{C}$ per $\mathrm{mg}$ carbon (103 amol ${ }^{14} \mathrm{C} / \mathrm{mg} \mathrm{C}$ ). The isotopic content of the lubrication oil was at instrumental background $\left(<0.1 \mathrm{amol}{ }^{14} \mathrm{C} / \mathrm{mg} \mathrm{C}\right)$.

FILTERS - All PM samples were collected on $47 \mathrm{~mm}$ Gelman Sciences PALLFLEX tissuquartz 2500QATUP membrane filters. These quartz filters were precombusted at $1173 \mathrm{~K}$ for $3 \mathrm{~h}$ to remove all carbon residue and allowed to $\mathrm{cool}$ to $300 \mathrm{~K}$ in the furnace before removal.

\section{METHODS}

ENGINE OPERATION - All engine tests were conducted at a medium load and speed, $285 \mathrm{~N}-\mathrm{m}$ (210 ft-lbs) at $1600 \mathrm{rpm}$. Fuel consumption and emissions were monitored.

FILTER HANDLING AND LOADING - Blank filters were first conditioned to temperature and humidity overnight in petri dishes and then individually weighed with a Mettler UM 3 microbalance. Before sampling, the dilution ratio was adjusted to 6.43 to yield temperatures of the diluted exhaust below the required $325 \mathrm{~K}$ (see Figure 1). Diluted exhaust was drawn through each filter for 12-24 minutes and the filters were then removed, placed in petri dishes and 


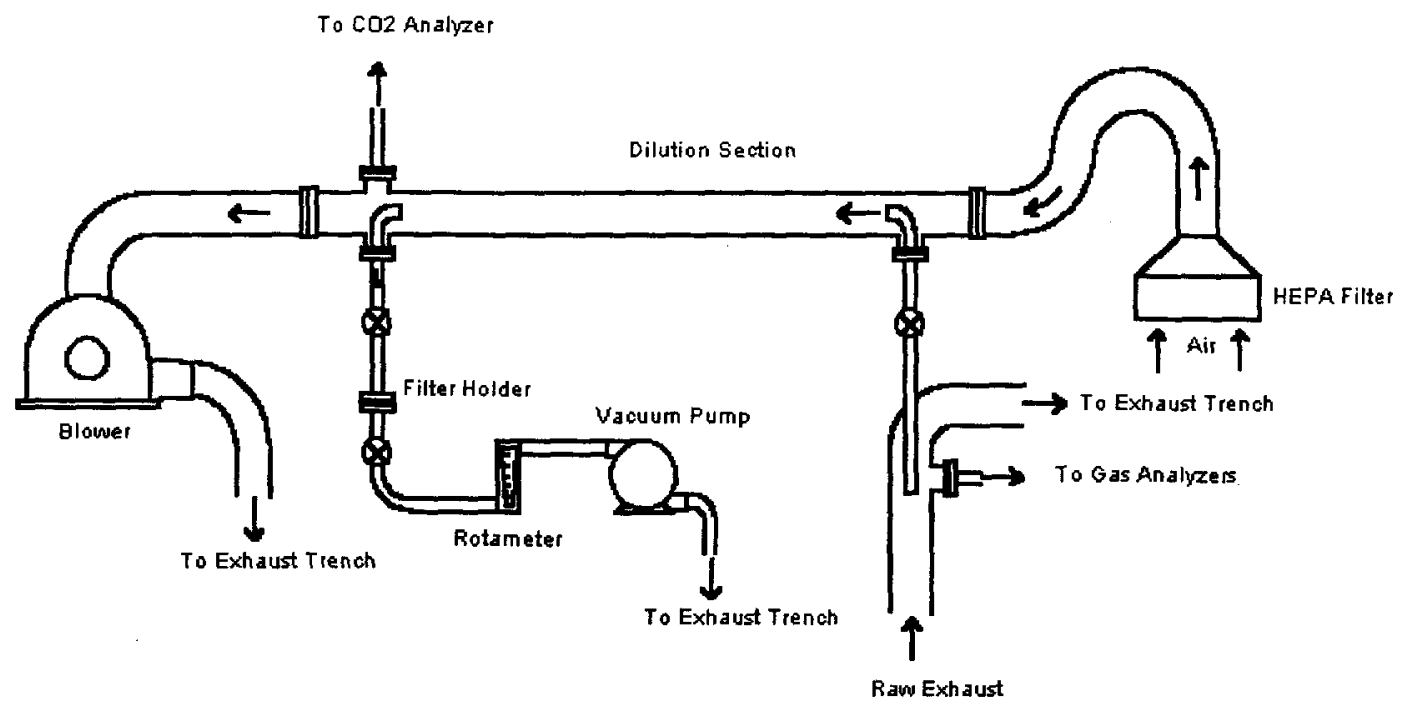

Flgure 1. Schematic of mini-dilution tunnel.

once again conditioned overnight before weighing. Four separate samples were taken.

GAS SAMPLE COLLECTION AND PROCESSING -Two gas samples were collected in $3.0 \mathrm{~L}$ Tedlar bags placed after the filter holder in the exhaust line. Each bag had a conventional fill valve and second septa seal port. The septa port was used to remove gas for AMS sample preparation. Gas samples were processed within several days of collection. The bags were maintained at temperatures between 290 and $300 \mathrm{~K}$.

The diluted exhaust gases contained $\sim 1 \% \mathrm{CO}_{2}$ and very low levels of $\mathrm{CO}$. Approximately $2-\mathrm{L}$ of diluted exhaust gas at atmospheric pressure was slowly bled through multiple cold traps that removed water (dry ice/isoprpanol) and trapped the $\mathrm{CO}_{2}$ (liquid nitrogen). The $\mathrm{CO}_{2}$ was then cryogenically transfered to a second liquid nitrogen cold trap and non-

- condensable gases were removed. The $\mathrm{CO}_{2}$ was then moved to a graphitization head [14] for conversion to an AMS graphite sample.

AMS FILTER PREPARATION - Beyond measuring total PM emissions, we sought to determine the susceptibility of PM to exhaust oxidation treatment to reduce mass. In practice, the criteria for this separation are operationally defined by the investigator. Depending on the field of the investigator, the separation of PM carbon is commonly described by the following pairs: elemental and organic carbon, soluble organic fraction (SOF) and insoluble organic fraction (IOF), or volatile organic fraction (VOF) and non-volatile organic fraction (NVOF). We prefer the VOF/NVOF nomenclature because it reflects the process we use and the physical properties employed in any realistic exhaust treatment scheme.
Loaded filters were cut in half with a clean stainless steel surgical scissors. Using our usual procedure [11], one half is cut into strips and placed in a quartz combustion tube with CuO oxidizer and converted to an AMS graphite sample [14]. This measurement is of the total carbon in the PM. The other half filter is heated to $613 \mathrm{~K}$ for $2 \mathrm{~h}$ in a furnace and then allowed to cool to room temperature. This procedure to remove the VOF was developed using National institute of Standards and Technology (NIST) standard reference material (SRM) to obtain consistent isotope ratios and mass fraction of the NVOF. NIST SRM 2975 (diesel soot) and SRM 1649a (urban dust) are the closest NIST SRMs to exhaust PM. The filters loaded with PM lose mass during the thermal separation and the soot deposits are noticeably lighter. The remaining carbon is the NVOF. The filters with NVOF are then prepared as AMS samples with the usual procedure [14].

Gravimetric measurement of PM deposited on filters can be unreliable if the PM mass is small $(100 \mu \mathrm{g})$ and the filter mass is large $(100 \mathrm{mg})$. During the AMS sample preparation method we measure the $\mathrm{CO}_{2}$ pressure from the completely combusted sample. The VOF is estimated by difference in carbon mass of the two half filters. The mass of adsorbed water is not an issue since water is removed before $\mathrm{CO}_{2}$ is measured.

The NVOF samples are most important when determining lubrication oil contribution to PM. Loaded filters readily adsorb volatile compounds when placed in the lab. In an engine lab, most of the volatile compounds are petroleum-derived. By thermally removing the VOF in the AMS sample prep lab, only the building blocks of the PM and low volatility large hydrocarbons remain for isotope measurement. The material sorbed onto the filters 
after loading is also removed in the VOF removal process.

AMS MEASUREMENT AND ANALYSIS - AMS is an isotope ratio mass spectrometry technique where ${ }^{14} \mathrm{C} /{ }^{13} \mathrm{C}$ ratios of the unknowns are normalized to measurements of 4-6 identically prepared standards of known isotope concentration. Typical samples are placed in quartz combustion tubes with excess copper oxide (CuO), evacuated and combusted to $\mathrm{CO}_{2}$. The evolved $\mathrm{CO}_{2}$ is purified, trapped, and reduced to graphite in the presence of cobalt or iron catalyst in individual reactors [14]. Large $\mathrm{CO}_{2}$ samples $\left(>500 \mu \mathrm{g}\right.$ ) can be split for additional ${ }^{13} \mathrm{C}$ measurement by stable isotope ratio mass spectrometry. Identified fuel components were measured for ${ }^{13} \mathrm{C}$ and gave $\delta^{13} \mathrm{C}$ corrections of -28 per 1000 . All graphite targets were measured at the Center for AMS at LLNL.

The isotope ratio of the sample, $R_{\text {sample, }}$ is calculated from the measured isotope ratios of the sample, $\mathrm{R}_{\text {sample(meas), the average of the measured standards, }}$ $\mathrm{A}_{\text {stand(maas), }}$ and the known isotope ratio of the standard, $R_{\text {stand, }}$ shown in Eq. 1.

$R_{\text {sample }}=\frac{R_{\text {sample(meas) }}}{R_{\text {stand(meas) }}} R_{\text {stand }}$

The measured ratio of ${ }^{14} \mathrm{C}$ to total $\mathrm{C}$ for each sample, $\mathrm{A}_{\text {samplas }}$ is described in Eq. 2 . The isotope concentration of the fuel component is ${ }^{14} \mathrm{C}_{\text {tuel }} / \mathrm{C}_{\text {tual }}$ while the contribution from the lubrication oil to the measured ratio is ${ }^{14} \mathrm{C}_{\mathrm{oil}} / \mathrm{C}_{\text {oil }}$. The background contribution is ${ }^{14} \mathrm{C}_{\mathrm{bk}} / \mathrm{C}_{\mathrm{bk}}$ and the possibility of contamination to the sample is indicated as ${ }^{14} \mathrm{C}_{\mathrm{uk}} / \mathrm{C}_{\mathrm{uk}}$ The background component of the gas sample is predominantly $\mathrm{CO}_{2}$ in the intake and dilution air while for filters it is due to $\mathrm{CO}_{2}$ and other compounds sorbing onto the filter loaded with PM.

$\mathrm{R}_{\text {sample }}=\frac{{ }^{14} \mathrm{C}_{\text {teol }}+{ }^{14} \mathrm{C}_{\text {oil }}+{ }^{14} \mathrm{C}_{\mathrm{bk}}+{ }^{14} \mathrm{C}_{\mathrm{uk}}}{\mathrm{C}_{\text {tuel }}+\mathrm{C}_{\mathrm{oll}}+\mathrm{C}_{\mathrm{bk}}+\mathrm{C}_{\mathrm{uk}}}$

In theory, all the components in Eq. 2 need to be determined by a series of control experiments. In practice some components can be minimized by experimental design. In the case of PM samples, the ${ }^{14} \mathrm{C}$ terms of petroleum derived oil is insignificant. The ${ }^{14} \mathrm{C}_{\mathrm{bk}}$ component is a systemic background of ambient $\mathrm{CO}_{2}$ absorbed by the deposited PM. It is hoped that $\mathrm{C}_{u k}$ is eliminated and $\mathrm{C}_{\mathrm{bk}}$ is consistently measured in blanks. In the case of gas samples, the fuel and air the major sources of carbon.

In our case, Eq. 2 collapses to a simple expression (Eq. 3) after we account for the appropriate backgrounds. The variable $\theta$ is then the ratio of $\mathrm{C}_{\text {oil }} /$ $\mathrm{C}_{\text {fuel. }}$

$$
R_{\text {sample }}=\frac{{ }^{14} C_{\text {tuel }}}{C_{\text {fuel }}+C_{\text {oil }}}=\frac{{ }^{14} C_{\text {tual }}}{C_{\text {fuel }}(1+\theta)}=\frac{R_{\text {tuel }}}{(1+\theta)}
$$

By first solving for $\theta$, we can then determine the fraction of carbon in the PM derived from lubrication oil, $F_{\text {oil }}$ (Eq. 4).

$F_{\text {oil }}=\frac{C_{\text {oil }}}{C_{\text {sample }}}=\frac{\theta}{1+\theta}$

\section{RESULTS}

All samples were easily measured by AMS. Sample sizes were moderate and isotope ratios were near contemporary levels, allowing high precision measurements.

FILTER ANALYSIS - The NVOF on all filters was clearly depressed in ${ }^{14} \mathrm{C}$ content compared to the fuel. Measurements of the isotopic content of the fuel completed on separate days were consistently at the contemporary ${ }^{14} \mathrm{C}$ content of $103 \mathrm{amol}{ }^{14} \mathrm{C} / \mathrm{mg} \mathrm{C}$. Table 3 summarizes the results indicating that lubrication oil contributed $4 \%$ of the carbon in NVOF PM.

Table 3. Summary of lubrication oil contribution to NVOF. The uncertainties in the averages are 1 standard deviation.

\begin{tabular}{|c|c|c|}
\hline Filter & $\begin{array}{c}\text { NVOF } \\
\left(\mathrm{amol}{ }^{14} \mathrm{C} / \mathrm{mg} \mathrm{C}\right)\end{array}$ & $\begin{array}{c}\text { Fraction NVOF } \\
\text { From Lube Oil }\end{array}$ \\
\hline 1 & $98.1 \pm 0.6$ & $4.8 \%$ \\
\hline 2 & $98.1 \pm 0.3$ & $4.8 \%$ \\
\hline 3 & $98.2 \pm 0.4$ & $4.8 \%$ \\
\hline 4 & $100.5 \pm 0.6$ & $2.4 \%$ \\
\hline Average & $98.7 \pm 1.2$ & $4 \pm 1 \%$ \\
\hline
\end{tabular}

GAS SAMPLE ANALYSIS- The isotope content of $\mathrm{CO}_{2}$ in combustion gas samples (102 \pm 0.5 amol ${ }^{14} \mathrm{C}$ / $\mathrm{mg} \mathrm{C}$ ) was slightly depressed from that of the fuel samples $\left(103 \pm 0.5 \mathrm{amol}{ }^{14} \mathrm{C} / \mathrm{mg} \mathrm{C}\right)$. Dilution of the exhaust with the ambient air in the dilution tunnel acçounted for the depression. The ambient air at the UCB Combustion Lab has a depressed ${ }^{14} \mathrm{C}$ ratio, typically $\sim 60 \%$ the contemporary value of 103 amol ${ }^{14} \mathrm{C} / \mathrm{mg} \mathrm{C}$. The ambient $\mathrm{CO}_{2}$ concentration was measured at $380 \mathrm{ppm}$. These values for the ambient $\mathrm{CO}_{2}$ are common in urban areas with high vehicle traffic. When the uncertainties in the measurements of fuel and $\mathrm{CO}_{2}$ are considered, the contribution of lubrication oil to $\mathrm{CO}_{2}$ was not significant.

\section{DISCUSSION}

In this study, the depression in isotope ratio was used to determine the contribution of lubrication oil to PM. The approach was successful due to the relatively large $(4 \%)$ contribution of lubrication oil to NVOF. It was a direct measurement of carbon from the lubrication oil under the speed and load used. It would probably be difficult to apply the procedure to engine operation under light loads due to the low PM levels produced. 
Ideally, a uniformly labeled lubrication oil would be used as a tracer with conventional fuel. The advantage is that the contribution of the lubrication oil to the PM would be easier to measure. Our approach here measured small differences in the contemporary ${ }^{14} \mathrm{C}$ background. In essence, we measured a small difference between two big numbers. Because AMS measurement precision is 5 parts per 1000 , we are confident that the depression in isotope content in the PM was due to the consumption of lubrication oil. The limitation of measuring the difference of two large numbers prevented the determination of lubrication oil in exhaust $\mathrm{CO}_{2}$

A suitably labeled lubrication oil would be a much better tracer. Lubrication oil labeled at 10-50 times the contemporary ${ }^{14} \mathrm{C}$ concentration would still not be a radioactive material [16], but its small contribution would be easier to measure against the ${ }^{14} \mathrm{C}$-free petroleum background of a conventional fuel. Here we would measure a small signal against an the instrumental background. If lube oil were labeled at 10 times the contemporary ${ }^{14} \mathrm{C}$ level and $2 \%$ of the PM were due to lubrication oil carbon, the PM would have a ${ }^{14} \mathrm{C}$ concentration of 20 amol ${ }^{14} \mathrm{C} / \mathrm{mg}$, a value 200 times above instrumental background. This is a huge signal for AMS and gives us approximately two orders of magnitude in usable signal to noise. A lubrication oil suitably labeled would allow measurernents of lube oil transport in exhaust at virtually all operation modes. Furthermore, labeled lubrication oil would enable PM size separation and apportionment of carbon to fuel or lubrication oil. Apportionment could continue to specific compounds separated and identified by gas chromatography and then quantified by AMS.

\section{CONCLUSION}

AMS provides a means of following the fate of carbon in specific compounds from the fuel or oil to the emissions from diesel engines. The sensitivity and precision of ${ }^{14} \mathrm{C}$-AMS overcame the limitations of using a labeled fuel to measure consumption of lubrication oil. Production of a universally labeled lubrication oil, preferably by polymerization of a small labeled base to produce uniformly labeled PAOs, is needed to thoroughly measure the transport of lubrication oil in the combustion chamber and out the exhaust head at all operation modes. A labeled lube oil will also enable particle size separation and apportionment to fuel or oil. The debate over the source of nano-particles could be quickly addressed.

\section{ACKNOWLEDGMENTS}

This work was performed under the auspices of the U.S. Department of Energy by University of California Lawrence Livermore National Laboratory under Contract No. W-7405-Eng-48. The engine experiments reported were conducted at The Combustion Laboratories of the Department of Mechanical Engineering at the University of California at Berkeley. The research at UC Berkeley was supported by LLNL Laboratory Directed Research and Development grant 01-ERI-007.

\section{REFERENCES}

1. Hanaoka et al., (1979) "New Method for Measurement of Engine Oil Consumption (STrace Method)", SAE Technical Paper 790936.

2. Bailey, B. K., Ariga, S., (1990) "On-Line Diesel Engine Oil Consumption Measurement", SAE Technical Paper 902113

3. Ariga, S., Sui, P.C., Shahed, S.M., (1992) "Instantaneous Unburned Oil Consumption Measurement in a Diesel Engine Using $\mathrm{SO}_{2}$ Tracer Technique", SAE Technical Paper 920652

4. Froelun, K., (1999) "Real-Time Steady-State Oil Consumption Measurement on Commercial SIEngine", SAE Technical Paper 1999-01-3461.

5. Foelund, K., Owens, E. C., Frame, E., Buckingham, J. P., Garbak, J., Tseregounis, S., Jackson, A., (2001) "Impact of Lubricant Oil on Fegulated Emissions of a Light-Duty MercedesBenz OM611 CIDI-Engine", SAE Technical Paper 2001-01-1901.

6. Okada, S., Kweon, C-B., Foster, D.E., Schauer, J.J., Shafer, M.M., Christensen, C.G., Gross, D.S. (2003) "Determining Oil Consumption via Exhaust Particulate Trace Metal Concentration: ICPMS and ATOFMS Measurements", SAE Technical Paper 2003-01-0076.

7. Bajpal, S., Logan, M.A., Stanley, R. (1999) "Measurement of Lubricating Oil Consumption Using Mg Tracer in a Medium-Speed Diesel Engine", SAE Technical Paper 1999-01-3572.

8. Püffel, P. K., Thiel, W., Boesl, U. (1999) "Application of a new Method for On-line Oil Consumption Measurement", SAE Technical Paper 1999-01-3460.

9. Buttini, P., Manni, M. (2001) “ Emissions of Deuterated Tracers from Oil in Light and Heavy Duty Diesel Engine", SAE Technical Paper 2001 . 01-3531.

10. Vogel, J.S., Turteltaub, K.W., Finkel, R., Nelson, D. E. (1995) "Accelerator Mass Spectrometry Isotope Quantification at Attomole Sensitivity", Analytical Chemistry 67: A353-A359.

11. Buchholz, B. A., Cheng, A. S., Dibble, A. W., Mueller, C. J., Martin, G. C. (2002) "Isotopic Tracing of Fuel Component Carbon in the Emissions from Diesel Engines", SAE Technical Paper 2002-01-1942. 
12. Buchholz, B. A., Cheng, A. S., Dibble, R W. (2002) "Isotopic Tracing of Bio-Derived Carbon for Ethanol-in-Diesel Blends in the Emissions of a Diesel Engine", SAE Technical Paper 2002-011704.

13. Roberts M.L., Bench, G.S., Brown, T. A., Caffee, M. W., Finkel, R. C., Freeman, S. P H. T., Hainsworth, L. J., Kashgarian, M., McAninch, J. E., Proctor, I. D., Southon, J. R., Vogel, J. S. (1997) "The LLNL AMS Facility," Nucl. Instru. Meth. B, 123: 57-61.

14. Vogel, J.S., Southon, J. R., Nelson, D. E. (1987) "Catalyst and Binder Effects in the Use of Filamentous Graphite for AMS," Nucl. Instrum. Methods Phys. Res. Sect. B 29: 50-56.

15. ASTM Standard D6751-02 (2002) Standard Specification for Biodiesel Fuel (B100) Blend Stock for Distillate Fuels.

16. 10 CFR 20.2005 (1991) Federal Register $56: 23403$.

\section{CONTACT}

Bruce A. Buchholz

Center for Accelerator Mass Spectrometry

Lawrence Livermore National Laboratory

P.O. Box 808, L-397

Livermore, CA 94551

USA

Voice: $1-925-422-1739$

FAX: 1-925-423-7884

Email: buchholz2@llni.gov

\section{DEFINITIONS, ACRONYMS,} ABBREVIATIONS

${ }^{12} \mathrm{C}$ : carbon-12, most common isotope of carbon, natural abundance $98.9 \%$

${ }^{13} \mathrm{C}$ : carbon- 13 , rare stable isotope of carbon, natural abundance $1.1 \%$

${ }^{14} \mathrm{C}$ : carbon-14, long-lived naturally occurring radioisotope of carbon, natural abundance 1.2 parts per $10^{12}$

AMS: accelerator mass spectrometry

amol: attomole, $1 \times 10^{-18}$ mole, $\sim 6 \times 10^{5}$ atoms

Isotope: Atoms of an element that differ in atomic mass. The nuclei of isotopes have the same number of protons but differnet numbers of neutrons

LLNL: Lawrence Livermore National Laboratory

NIST: National Institute of Science and Technology

NVOF: non-volatile organic fraction
PAO: poly-alpha-olephin

PM: particulate matter

SRM: standard reference material

UCB: University of California at Berkeley

universal isotopic label: isotope used as labeled tracer is distributed uniformly throughout a molecule

VOF: volatile organic fraction 